\title{
Information security - challenges for the next millennium
}

\author{
A. K. Stanley \\ Managing Director \\ European Security Forum \\ Plumtree Court, London EC4A 4HT, England \\ Tel: +44171213 4671, Fax: +441712134813, \\ E-mail alanstanley@securityforum.org
}

\begin{abstract}
This paper looks at the key challenges in information security in the years ahead from the perspective of a leading business organisation. Four particular areas are addressed - awareness and management commitment, risk analysis, security architecture and cryptography. For each area the current status, issues and challenges are discussed.
\end{abstract}

\section{Keywords}

Information security, awareness, management commitment, security architecture, cryptography.

\section{INTRODUCTION}

Information security is a challenging topic at the best of times. It is a complex, wide ranging subject that has to deal with a computer and network environment which is developing very rapidly. In a business context, information security has to support key business processes and those involved with information security need a good grasp of how businesses operate. Information security also has great depth as it covers subjects from high level principles and policy right down to the very detailed calculations in encryption algorithms. It covers computers, networks, system software, application 
software and information itself. Its practices and procedures cover physical security, access control, continuity planning, secure systems development, cryptography and much more. It is, in short, one of the most intellectually challenging topics I know.

We are at the dawn of a new age - the 'Information Age'- which is likely to change and challenge may of our current practices and business processes - an age of exciting and far reaching developments. And the key factor that will underpin these developments is information security. It is information security that will provide the trust necessary for the information age to blossom.

There are exciting opportunities and challenges ahead in the field of information security - challenges for user organisations, suppliers, governments and for all individuals involved with information security. However, I am going to focus my talk on the business world and look at topics from the perspective of the user organisation.

Much of my thinking is based on my time with the European Security Forum and the work the Forum has conducted over the last eight years. I will be drawing statistics from the information security status survey conducted by the Forum amongst its Members. In my presentation at the conference, I will provide more detailed charts and statistics. But firstly, what is the Forum? The European Security Forum is an association of leading organisations, currently numbering over 150 organisations from 13 countries, dedicated to clarifying and resolving key issues in information security and developing security solutions that meet the needs of its members. It is independent and non-profit making in the sense that any surplus of income over expenditure is ploughed back in to support the next year's programme. Members of the Forum agree a work programme and collaborate and participate actively in Forum projects. Over the last eight years the Forum has spent over ECU $6.5 \mathrm{~m}(\$ 13 \mathrm{~m})$ on addressing issues in information security.

\section{CHALLENGES}

In looking ahead and determining what challenges will be faced by those associated with information security as we enter the next millennium, I have chosen four areas as follows:

- awareness and management commitment which form the foundation of any serious approach to information security;

- risk analysis which builds on awareness and commitment and plays a key part in ensuring that business managers understand information security risks and what to do about them;

- security architecture which focuses on the management of security in a distributed environment;

- cryptography which, although not used widely today, will form the basis of secure electronic commerce and the development of the information society. 


\section{AWARENESS AND MANAGEMENT COMMITMENT}

Achieving a high level of security across an organisation is very dependent on staff awareness at all levels and on the commitment of top management. While progress has been made in this area and awareness about information security has risen, partly due to concerns about the security of the Internet, there is still room for improvement. In the Forum survey, over $90 \%$ of members have a corporate information security policy although only three quarters of them were ratified at board level. Yet, when asked about top management's commitment to chairing key working groups, only $30 \%$ of members were rated strong or very strong. In many organisations, senior individuals pay lip service to information security or do not fully accept their responsibilities by saying 'I've got someone who looks after that'.

I believe that a major reason for this is to do with security metrics. In information security there is a scarcity of good information about such things as security incidents, likelihood of occurrence and the effectiveness of controls. In the Forum's survey the worst rated area was 'monitoring performance and plans' and within this area, the weakest sections were to do with establishing performance indicators and the fact gathering process. Very few organisations have a coherent process for measuring security at a detailed level and reporting on it at, for example, a department, business unit, company and group level.

The challenge in this area is to keep the level of awareness growing and to gain a real commitment from top management. In support of this, significant work is needed in the area of security metrics. In addition, the development of best practice for top management could be of substantial help. For example, if the board of an organisation reviewed the organisation's security status twice a year, it would demonstrate the importance of information security and provide a real incentive to fix any problem areas.

\section{$4 \quad$ RISK ANALYSIS}

One of the ways that business managers can become more aware of the issues in information security is by using risk analysis. A formal, well-structured process for looking at information security risk can enable business managers to understand the risks involved and agree what measures to control risks are worthwhile.

Although progress in this area has been made, it remains an area where there is significant room for improvement. In the Forum's survey it is one of the weakest areas both in terms of identifying and valuing information assets and in conducting the risk analysis process itself. However, there are signs that improvements are being made. 
The Forum has done considerable work on risk analysis including:

- a report on how to establish a satisfactory risk analysis process

- SARA, a risk analysis methodology for critical business applications

- OSCAR, which captures risk analysis information

- SPRINT, a simplified version of SARA for important, but not critical, systems

- a report on how to build security into the systems development process.

Many Forum members are using the above tools and reports and it is encouraging that members have made risk analysis a priority over an extended period.

The challenge in this area is to make risk analysis part of every day practice so that every new or significantly modified application has a risk analysis conducted as a matter of course. Ideally business managers should see it as part of their responsibility to instigate the process. Perhaps one of the security metrics reviewed by senior management could be the number of risk analyses conducted by the organisation. A further challenge is to make the analysis of risk in information systems consistent with the processes the organisation uses to evaluate risk in other areas such as insurance or credit risk. Real progress will have been made when information security risk is dealt with alongside other business risks.

\section{SECURITY ARCHITECTURE}

Managing security across a distributed, multi-vendor environment is a difficult task made more difficult because of a lack of standards and tools. A coherent security architecture describing how users can be given access, in a controlled way, to applications, transactions and data would be a considerable step forward. However, currently there is little or no agreement on where and how control should be excercised - at the operating system level? using the access control software? via the database? in the application itself? or in the communications network?

In the Forum's Status Survey, only half the members say they have a security architecture. Of those that do, $40 \%$ do not have a common user ID and $75 \%$ do not have single sign-on to corporate systems. Clearly there is much to be done!

The topic of security architecture is complicated further by issues such as:

- single sign-on

- distributed security administration

- client/server applications

- groupware

- emerging standards such as X/Open's distributed computing environment (DCE) and their Baseline Security Standard (XBSS)

- a lack of user input into the standards process. 
Also, I believe, a major reason why progress has not been more rapid is the difficulty of explaining to senior business managers exactly what the problem is and why a security architecture is a key element of the solution. The timeframe for a solution tends to be outside a business manager's horizon and therefore not something to which funds can be allocated now.

In addition, solutions need to be agreed by many parties (users, suppliers and standards bodies) internationally and this takes time.

Without a well-thought-through, coherent, practical security architecture, managing security in a distributed environment will become an increasingly difficult and time consuming task and one which is likely to result in errors and security weaknesses. The challenge in this area is to recognise the current situation, to communicate with business managers and to ensure that resources are allocated and to work with others towards a solution. User organisations can play an important role in raising the importance of this topic and helping to develop a practical solution.

\section{CRYPTOGRAPHY}

The use of cryptography across the business community is currently quite small. In the Forum's Status Survey, only 6\% of Forum members use digital signatures, only $9 \%$ use message authentication codes and two thirds do not encrypt sensitive information. However, it is likely that the use of cryptography will grow substantially as electronic commerce, homeworking/teleworking, direct customer interfaces and automated supply and delivery channels develop.

The security features or services needed to provide trust in this electronic marketplace can be summarised as follows:

\section{Table 1}

Security service

- confidentiality

- integrity of data

- authenticity of data

- non-repudiation of electronic messages

- proof of originality

- proof of identification

\section{What it provides}

ensuring information can only be seen by authorised individuals

ensuring that information cannot be maliciously modified

ensuring that it is possible to identify the originator of information

ensuring that neither the sender nor the recipient of a message can subsequently deny the fact

ensuring that an electronic document is the original version and not a copy ensuring that an individual is who they claim to be when accessing electronic systems 
Currently, the only effective way of providing these services is by using Cryptography which will therefore become the key technology for establishing a secure network infrastructure.

But dealing with cryptography is not a simple process:

- most organisations have little or no experience of using cryptography (banks are, of course, the exception);

- managing cryptographic keys can be very complex;

- many countries impose import, export and/or use controls on cryptography;

- a global approach to cryptography policy is just emerging via the OECD;

- new terminology and processes are emerging such as trusted third party, key escrow and certification authority;

- new laws may be required governing such things as digital signatures.

The challenges ahead in cryptography will be significant. Individual organisations will need to learn where and when to apply cryptography. They will also need to develop a corporate policy on the use of cryptography and establish a framework for managing cryptography across their organisation and with their trading partners. Business and Governments will have to work together internationally to develop common, practical procedures so that cryptographic processes can support electronic commerce in the global marketplace. Individuals will be challenged to keep abreast of developments and to play a part in ensuring that solutions are practical and effective.

\section{BIOGRAPHY}

Alan Stanley is the Managing Director of the European Security Forum, an independent non-profit making association of leading organisations from 13 countries with some 150 members. He has been working in the area of information security for man years and was coauthor of a major $£ 1 \mathrm{~m}$ study on information security in commercial organisations, cofunded by the European Commission and 40 major organisations. Subsequently he was responsible for establishing and managing the Forum which, over the last eight years, has spent over $£ 9 \mathrm{~m}$ undertaking research into information security and providing practical authoritative information to its members. Alan has over 20 years experience in information technology and has a degree in mathematics from Manchester University in England, and an MBA from York University in Canada. He has lectured and conducted consulting assignments in Europe and North America. 